\title{
Liquefaction Behaviors of Oil Palm Frond and Bamboo in 1-Butyl-3-Methylimidazolium Chloride
}

\author{
Zhong Sheng Tai, Mohd Asmadi*, Noorhalieza Ali \\ Department of Chemical Engineering, Faculty of Chemical and Energy Engineering, Universiti \\ Teknologi Malaysia, 81310 UTM Johor, Malaysia
}

Received: $28^{\text {th }}$ November 2017; Revised: $4^{\text {th }}$ June 2018; Accepted: $9^{\text {th }}$ June 2018; Available online: 14 $4^{\text {th }}$ November 2018; Published regularly: December 2018

\begin{abstract}
Oil palm and bamboo are two of the most widely used biomass in the world nowadays as they can be converted into many valuable products. However, they are very difficult to be hydrolyzed and converted into other products because of their tight and strong hydrogen bonding between the lignin and polysaccharides. Ionic liquid (IL) is said to be the most ideal solvent to dissolve those biomass. Thus, in this research, 1-butyl-3-methylimidazolium chloride ([BMIM][Cl]) was chosen to liquefy oil palm frond $(\mathrm{OPF})$ and bamboo. The objective of this research was to compare the reaction behaviors of OPF and bamboo in $[\mathrm{BMIM}][\mathrm{Cl}]$ at different treatment time. $\mathrm{OPF}$ and bamboo were heated at $120{ }^{\circ} \mathrm{C}$ for $2-24$ hours under atmospheric pressure. Two fractions were obtained, namely [BMIM][Cl]-soluble and -nonsoluble. The non-soluble fractions were characterized using TGA, FTIR, XRD and FESEM while the soluble fractions were analyzed using HPLC. Based on the results obtained from the analyses, the effectiveness of [BMIM][Cl] in dissolving OPF was higher than bamboo as it was made up of less complex and compact cell wall structure. This structure allowed the diffusion of [BMIM][Cl] into the interior of OPF more easily to break down the hydrogen bonding network. Holocelluloses and lignin of OPF solubilized into [BMIM][Cl] more rapidly due to the greater distortion in hydrogen bonding network of the cell wall with the increase in treatment time compared to bamboo. Moreover, the mono-sugars of OPF were formed much easily than bamboo after short period (2 hours) of treatment. Copyright (C) 2018 BCREC Group. All rights reserved
\end{abstract}

Keywords: Oil Palm Frond; Bamboo; Ionic Liquid; Liquefaction; Dissolution

How to Cite: Tai, Z.S., Asmadi, M., Ali, N. (2018). Liquefaction Behaviors of Oil Palm Frond and Bamboo in 1-Butyl-3-Methylimidazolium Chloride. Bulletin of Chemical Reaction Engineering \& Catalysis, 13 (3): 447-455 (doi:10.9767/bcrec.13.3.1085.447-455)

Permalink/DOI: https://doi.org/10.9767/bcrec.13.3.1085.447-455

\section{Introduction}

Oil palm is originated from West African tropical rainforest. It is one of the most widely used biomass in the world. It is mainly used for the industrial production of vegetable oil [1].

* Corresponding Author.

E-mail: mohdasmadi@utm.my (M. Asmadi)
Malaysia and Indonesia are the main producers and suppliers of palm oil in the world, accountting for $85 \%$ of the world's palm oil production [2]. The main three parts of oil palm which can be converted into products of high economical values are empty fruit bunch (EFB), oil palm frond (OPF) and palm kernel. Oil palm is mainly composed of cellulose and hemicellulose [3]. The complex hydrogen-bonding network within 
lignocellulose of oil palm makes it resistive to chemical and enzymatic treatment. Thus, it is very difficult to be converted into more valuable products.

Bamboo is a perennial woody grass which grows abundantly in most of the tropical countries with warm climate, abundant moisture and productive soil [4]. Bamboo grows very fast and matures quickly. Its fast growth characteristic gives it the potential to be the widely used renewable resources. Bamboo is commonly used in many Asian countries like China and Japan. It plays a vital role in the building constructions and household utilities [5]. Just like other biomass, it is made up of cellulose, hemicellulose, lignin, and other minor constituents [6].

Cellulose is the main constituent in the plant cell wall. It is highly crystalline and this makes it invulnerable to many degradation reactions [7]. Lignin plays a vital role in protecting the cellulose and hemicellulose from microbial attack [8]. The extensive cross-linking hydrogen network linking the lignin with carbohydrates in the plant cell wall hinders the enzymatic degradation reactions. Thus, pretreatment is needed to disrupt the structure of lignocellulose to make the cellulose more accessible to hydrolysis reactions. Various methods of pretreatment of lignocellulose have been studied but each has its own disadvantages. For example, biological methods require long treatment time while chemical methods are hazardous and corrosive [9].

Recently, ionic liquid (IL) has become the favor due to its promising characteristics for dissolution of cellulose. This green solvent has low melting point, thus it is in liquid state at room temperature. Besides, the low viscosity, nonvolatile, chemically stable, non-toxic, recyclable and high solvating power characteristics make it the most suitable solvent for the pretreatment of lignocellulose [10-13]. ILs can be categorized into four groups which includes chiral ionic liquid (CIL), protic ionic liquid (PIL), task specific ionic liquid (TSIL), and switchable ionic liquid (SIL). These ILs have their own promising and unique characteristics and therefore they have brought significant impacts on the engineering field.

Several comparative studies have been reported on the reaction of different woods in ionic liquids [14-17]. Yooko and Miyafuji [15] found that Japanese beech was liquefied more easily in 1-ethylpyridinium bromide, [EtPy][Br] compared to Japanese cedar. The authors attributed such significant difference to the differences in the chemical structures of the hemi- cellulose and lignin in both woods. Similar results were also reported by Nakamura et al. [16] on the easier liquefaction of Japanese beech in 1-ethyl-3-methyl-imidazolium chloride, $[\mathrm{EMIM}][\mathrm{Cl}]$ than that of Western cedar due to the higher $\beta$-O-4 linkages in the former wood type. This clearly demonstrated that the solubility of different biomass in IL systems is different due to the difference in the chemical structures.

Although there are several studies on the pretreatment of OPF and bamboo using ILs [18 -21], the comparison between the reaction behaviors of these two abundant biomasses in ILs have yet to be reported. Hence, in this studies, the difference in the reaction behaviors between OPF and bamboo in 1-butyl-3methylimidazolium chloride [BMIM][Cl] at different treatment time were investigated.

\section{Materials and Methods}

\subsection{Materials}

$\mathrm{OPF}$ and bamboo were dried and grinded into smaller size using electrical mill. After that, the grinded samples were screened using sieve with the opening diameter of 500 to $800 \mu \mathrm{m}$ mesh. The samples were then extracted with ethanol using soxhlet extractor for 8 hours, followed by oven drying at $105{ }^{\circ} \mathrm{C}$ for 24 hours. Ethanol and [BMIM][Cl] were purchased from Sigma-aldrich, Germany, while sucrose, glucose, galactose, mannose, xylose, arabinose and fructose were purchased from Merck, Germany.

\subsection{Liquefaction with [BMIM][Cl]}

$0.30 \mathrm{~g}$ of extractive-free OPF samples was heated with $9.00 \mathrm{~g}$ of [BMIM][Cl] in threenecks bottles at $120{ }^{\circ} \mathrm{C}$ for various treatment times from 2-24 hours under atmospheric pressure. After the liquefaction process, the products were cooled prior to filtration. During filtration, the products were washed using some distilled water and separated using vacuum filter with $0.45 \mu \mathrm{m}$ membrane filter paper. Two fractions were obtained, namely [BMIM] $[\mathrm{Cl}]$-soluble and -nonsoluble. Then, both fractions were dried for 24 hours to remove the excess distilled water. The procedure was repeated to liquefy the bamboo samples.

\subsection{Analysis of Products}

Perkin Elmer TGA 4000 was used to measure the change in mass of the samples as a function of time. The samples was placed in 
the aluminium oxide $\left(\mathrm{Al}_{2} \mathrm{O}_{3}\right)$ crucible and heated from the temperature of 30 to $900{ }^{\circ} \mathrm{C}$ under nitrogen, $\mathrm{N}_{2}$ flow with a heating rate of $10{ }^{\circ} \mathrm{C}$ $\min ^{-1}$. The chemical bonds in OPF and bamboo samples molecules were identified via Fourier Transform Infrared Spectroscopy (FTIR). Perkin Elmer 180 FT-IR spectrophotometer with wavelength of $400-4000 \mathrm{~cm}^{-1}$ with 16 times of scanning was used to determine the infrared spectra of the original and residue non-soluble products of $\mathrm{OPF}$ and bamboo. These samples were prepared using $\mathrm{KBr}$ pellet techniques. Field Emission Scanning Electron Microscopy (FESEM) was used to identify the molecular of OPF and bamboo via Zeiss Supra 35 VP Field Emission Scanning Microscope. The original $\mathrm{OPF}$ and bamboo samples and their nonsoluble products were stuck on coins and then coated with gold palladium using Cool Sputter Coater (Bio-Rad) Polaron Division at $20 \mathrm{~mA}$ per second. The change of the morphological structures of the samples in different treatment times was observed, analyzed and compared. The behaviors of crystalline structure of the samples were identified based on their diffraction pattern using X-Ray Diffraction (XRD). The patterns of the OPF and biomass samples were obtained via the Siemens D5000 Goniometer using $\mathrm{Cu}-\mathrm{K}_{\mathrm{a}}$ radiation $(\lambda=1.54056 \mathrm{~nm})$ at $40 \mathrm{kV}$ and $30 \mathrm{~mA}$. The range of the scanning angle was from $10^{\circ}$ to $80^{\circ}$ with a scan-step of $0.05^{\circ}$ per second.

Mono-sugars in soluble products were determined using Agilent 1260 Infinity High Performance Liquid Chromatography (HPLC) under

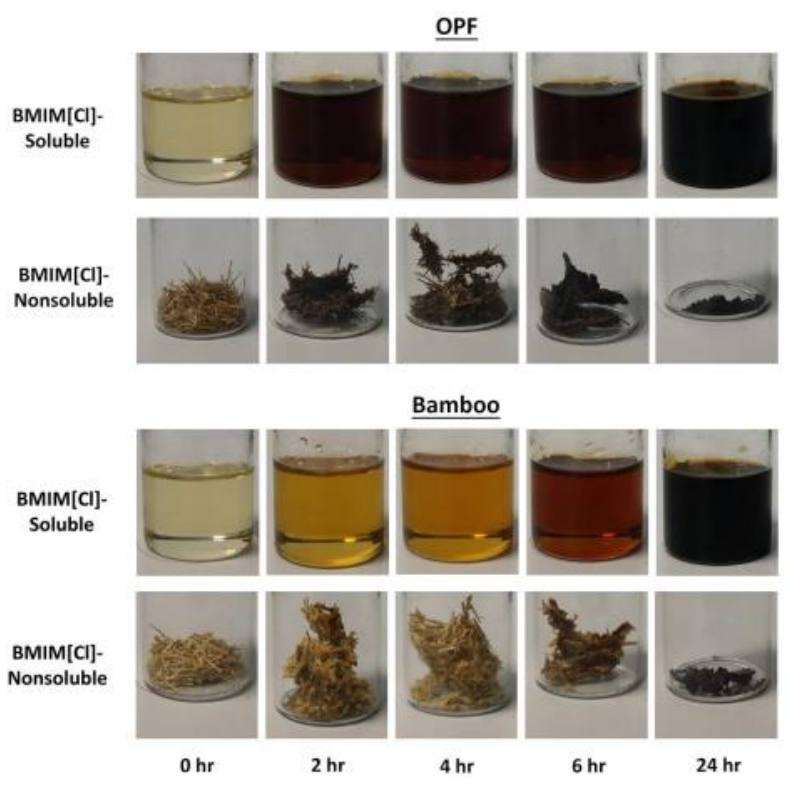

Figure 1. Images of [BMIM] $[\mathrm{Cl}]$-soluble and nonsoluble products of OPF and bamboo the following conditions: column, Rezex RCMMonosaccharide $\mathrm{Ca}^{+2}(8 \%)$ with $300 \times 7.80 \mathrm{~mm}$ in dimensions; flow rate, $0.6 \mathrm{~mol} / \mathrm{min}$; injection volume, $20 \mu \mathrm{L}$; running time, 30 minutes; mobile phase, deionized water; detector, refractive index detector (RID); column temperature, 75 ${ }^{\circ} \mathrm{C}$. The standard sugars used were sucrose, glucose, galactose, mannose, xylose, arabinose and fructose, which all were diluted using distilled water at $300 \mathrm{ppm}$ and of six dilution factors (DF).

\section{Results and Discussion}

3.1 Images of [BMIM][Cl]-soluble and nonsoluble

The color changes of [BMIM][Cl]-soluble and -nonsoluble fractions of OPF and bamboo before and after the liquefaction process are depicted in Figure 1. The color changes could be obviously seen from the [BMIM][Cl]-soluble fraction. Initially, the color of pure [BMIM][Cl] was clear. After 2 to 6 hours of IL treatment, the color of the liquid changed from clear to darker color. For OPF, the [BMIM][Cl]-soluble fraction changed from clear (untreated) to dark brown. On the other hand, the color of bamboo changed to light brown color at 2 to 6 hours. Thus, the color change of OPF was faster than bamboo as it changed to dark color after 2 hours of treatment. It could be related to the more rapid dissolution rate of OPF into [BMIM][Cl] than bamboo. After 24 hours of treatment, the color of soluble fraction for both $\mathrm{OPF}$ and bamboo turned to black. Thus, from the color changes of both biomass, it could be said that the solubilization of the polymers in $[\mathrm{BMIM}][\mathrm{Cl}]$ increased along the treatment time as they became darker in color because the ordered structure of biomass cell wall was disrupted which are discussed in detail in Section 3.3.

As for the insoluble fraction, the color of OPF solid residue changed from light (untreated) to dark color after 2 to 6 hours of treatment. In contrary, there was no obvious color change for bamboo solid residue because bamboo dissolved slower in [BMIM][Cl] treatment leading to less visible color change of the solid residue. After 24 hours of prolonged treatment time, the color for both OPF and bamboo became black and there was a significant decrease in the amount of solid residue which indicates that both biomass had dissolved in [BMIM] $[\mathrm{Cl}]$. 
3.2 Compositional Changes of BMIM][Cl]soluble and -nonsoluble

The compositional changes of [BMIM][Cl]soluble and -nonsoluble of OPF and bamboo are shown in Figure 2. The soluble products of OPF and bamboo increased along the treatment time. The weight percentage of OPF soluble product increased more rapidly than bamboo at the treatment times of 2 to 24 hours. The soluble product of OPF increased $83.3 \mathrm{wt} \%$, while it was $76.7 \mathrm{wt} \%$ for bamboo after 24 hours of [BMIM] [Cl] treatment.

The cellulose and hemicellulose region for both OPF and bamboo decreased along with the increase in treatment time. This shows the degradation of cellulose due to the attack of $\mathrm{Cl}^{-}$ anion of [BMIM][Cl] against the polysaccharides causing the breakdown of cellulose chain $[22,23]$. Thus, the solubilization of polymer into [BMIM] [Cl]-soluble fraction increased. It could be clearly observed that cellulose and hemicellulose content in OPF [BMIM][Cl]-nonsoluble decreased more rapidly than bamboo along the treatment time.

As for lignin region, a significant amount of lignin solubilized into the [BMIM][Cl]-soluble fraction after prolonged treatment. This could be due to the cracking of cell structure of both biomass causing the loss of lignin into the soluble fraction [24]. For OPF, a notable amount of $15.7 \mathrm{wt} \%$ dissolved in [BMIM][Cl] while it was only 10.8 wt\% for bamboo after 24 hours of treatment.

The difference in [BMIM][Cl]-soluble and -nonsoluble compositions of OPF and bamboo could be due to the different cell wall structure of both biomass. A previous study reported that the dissolution rate of a biomass was slower when the cell wall structure was complex as this reduced the effectiveness of diffusion of IL into its interior to break down the tight hydrogen bonding between the lignin, cellulose and hemicellulose [14]. OPF has less compact cell wall structure compared to bamboo and this had been suggested in FESEM analysis (will be discussed later). Thus, it dissolved more rapidly in [BMIM][Cl] than bamboo with the rapid decrease in the amount of polysaccharides and lignin in non-soluble fraction.

\subsection{Characterization of [BMIM][Cl]-nonsoluble}

The thermal behaviour of OPF and bamboo in [BMIM][Cl] for 0-24 hours are shown in Figures 3 and 4. From TGA curves, the weight percentage change for OPF was found to be lower for 2 to 6 hours compared to 0 hour while it was greater for bamboo. This difference could be due to different types of lignin in those biomasses. According to Jakab et al. [25], the ether bonds between the syringyl lignin units are easily to be broken compared to those of guaiacyl lignin units. Hence, the biomass with greater amount of guaiacyl lignin demonstrates higher thermal stability compared to those with higher syringyl lignin content. The untreated OPF might contain higher amount of syringyl lignin which was easier to be decomposed; hence resulting in greater weight percentage loss compared to those of after treatment for 2 to 6 hours. On the other hand, the syringyl to guaiacyl lignin ratio of untreated bamboo might be lower which bestowed it with greater thermal stability compared to those of after treatment for 2 to 6 hours.

The initial holocellulose decomposition temperature of $\mathrm{OPF}$ was found to be $200{ }^{\circ} \mathrm{C}$ before treatment while it was $220^{\circ} \mathrm{C}$ for bamboo. The initial holocelluloses decomposition tempera-
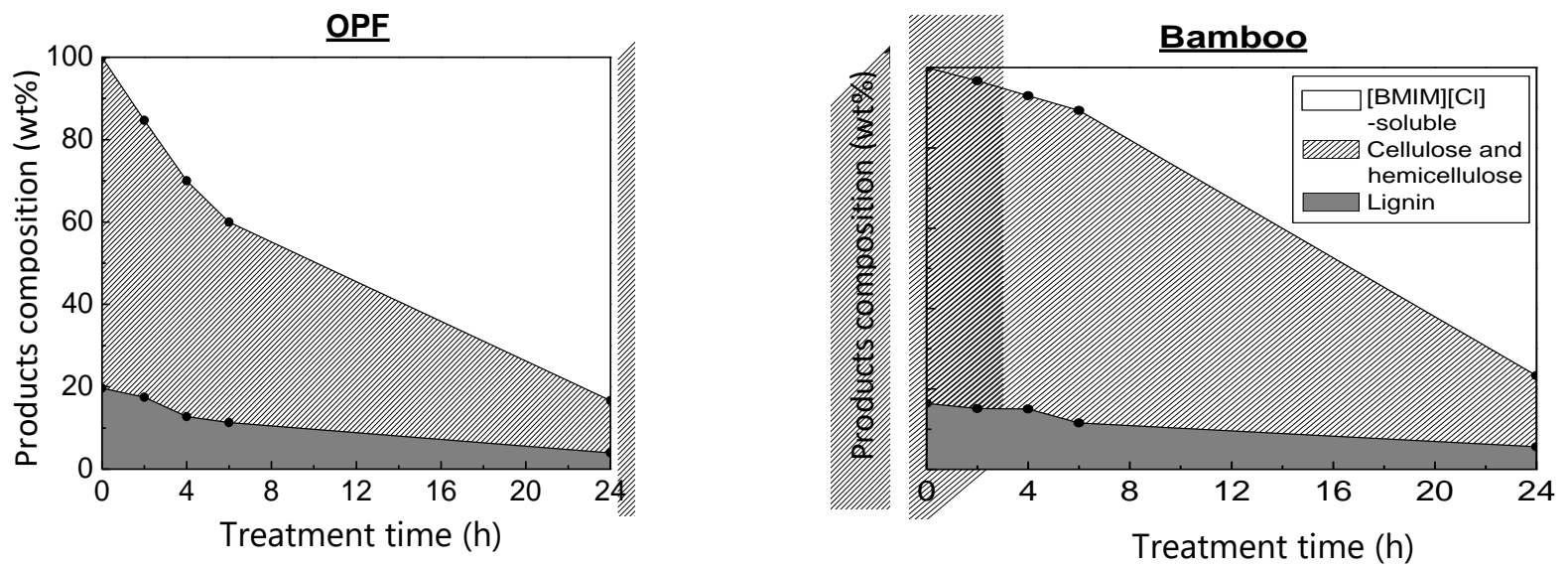

Figure 2. Compositional changes of [BMIM][Cl]-soluble and -nonsoluble (cellulose and hemicellulose, as well as lignin) products of $\mathrm{OPF}$ and bamboo 
ture was observed to decrease along the treatment time and this could be related to the loss of some residue molecules during the liquefaction process [26]. After 24 hours of treatment, the initial holocelluloses decomposition temperatures of $\mathrm{OPF}$ and bamboo decreased to $180^{\circ} \mathrm{C}$. The hydrogen bonding network was weakened due to the IL treatment causing the holocelluloses to be decomposed more easily at lower temperature.

As for DTG curves, the degradation temperature for cellulose in untreated OPF and bamboo was 346 and $357^{\circ} \mathrm{C}$, respectively. The higher degradation temperature of bamboo indicates its stronger bonding within the lignocellulose. After prolonged treatment times, the cellulose degradation temperatures were shifted to lower temperature, which were 266 and 282 ${ }^{\circ} \mathrm{C}$ for OPF and bamboo, respectively. The shifting of peaks of treated samples to lower temperatures was due to the lower crystallinity of the samples causing the thermal stability to decrease [24]. The larger shifting of peaks for
$\mathrm{OPF}$ from 346 to $266{ }^{\circ} \mathrm{C}$ signifies the greater degree of distortion on hydrogen bonding network of cellulose by [BMIM][Cl]. Meanwhile, DTG curves for both OPF and bamboo became one peak after longer treatment time, which could be related to the higher solubilization of polymer in [BMIM][Cl]. After prolonged IL treatment, hemicellulose content in the residue maybe become insignificant, causing the occurrence of one peak in DTG curves.

Figure 5 shows the FTIR spectra for the $\mathrm{OPF}$ and bamboo before and after treatment and the absorbance band is shown in Table 1 . An absorbance centered at $3433 \mathrm{~cm}^{-1}$ was corresponded to the $\mathrm{O}-\mathrm{H}$ groups [18,26]. This was due to the presence of intra- and intermolecular hydrogen bonding within OPF and bamboo samples. The peak intensity became lower after IL treatment because of the disruption in the hydrogen bonding network, which also signifies the reduction in the crystallinity of cellulose. The sharper peak of untreated OPF and bamboo was due to the strong crystal-
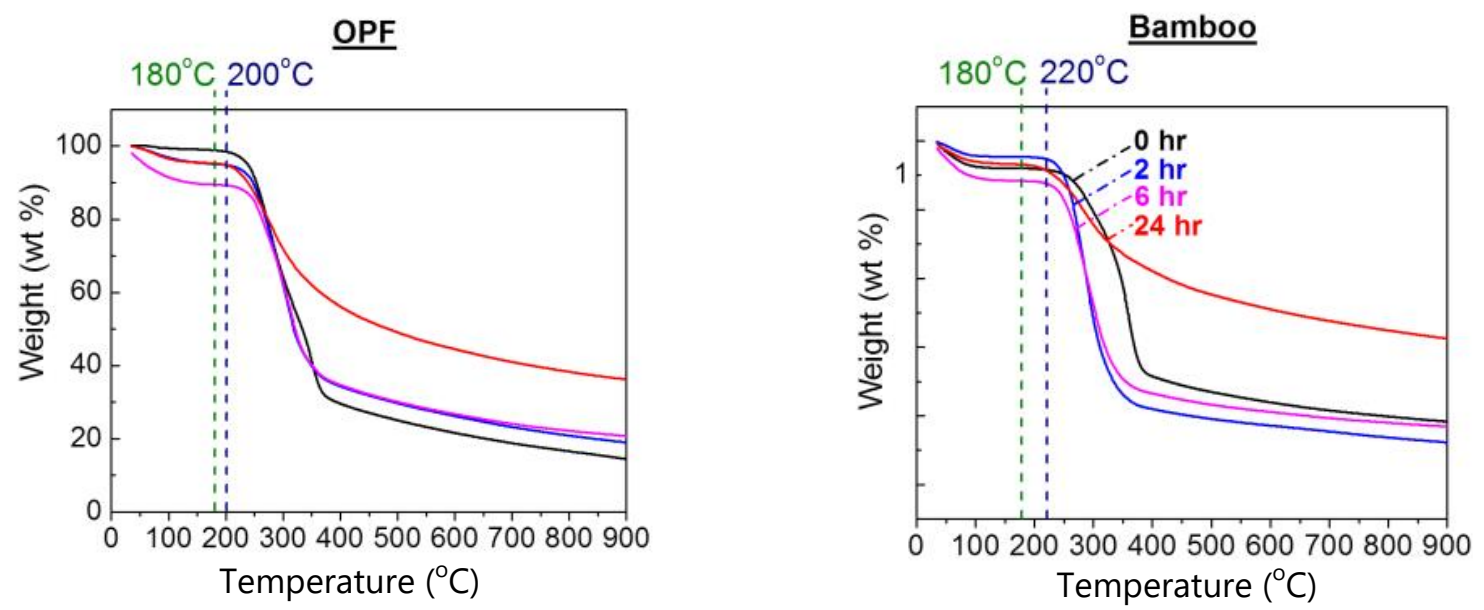

Figure 3. TGA curves of the non-soluble untreated and treated OPF and bamboo
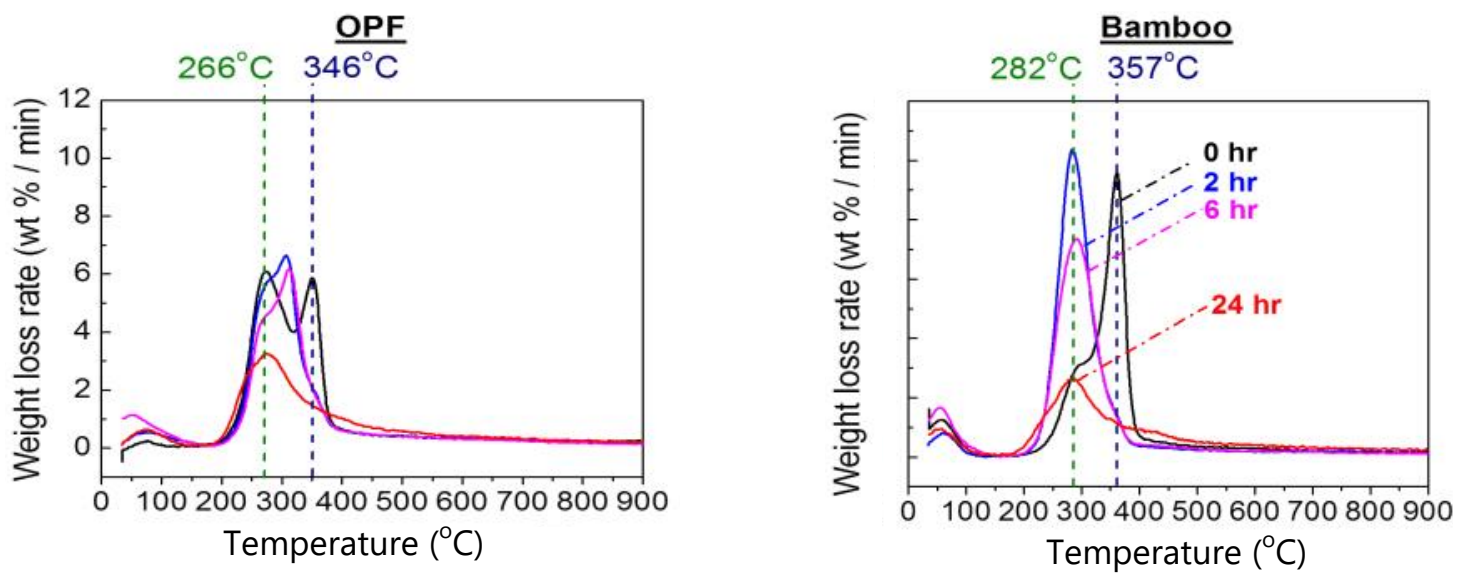

Figure 4. DTGA curves of the non-soluble untreated and treated OPF and bamboo 
line structure of the cellulose. In contrary, the amorphous treated biomass produced broader peak, and this was consistent with the previous study [27].

Meanwhile, an absorbance band centered at $1050 \mathrm{~cm}^{-1}$, which indicates the presence of $\mathrm{C}-\mathrm{O}$ stretching vibration in cellulose / hemicellulose. Besides, the absorbance band at $895 \mathrm{~cm}^{-1}$, which was assigned to $\mathrm{C}-\mathrm{H}$ deformation vibration that derived from cellulose II, happened to be more intense after the treatment [18]. This was related to the conversion of crystalline cellulose I into non-crystalline structure. The cell wall of structures of both biomass were distorted and lost their crystalline form during the treatment with [BMIM][Cl] and was then restructured into non-crystalline structure [26]. $\mathrm{OPF}$ demonstrated more intense $\mathrm{C}-\mathrm{H}$ deformation vibration than bamboo because it was easily to be distorted to form amorphous cellulose when treated with [BMIM] $[\mathrm{Cl}]$.

An absorbance band indicating the acetyl group $(\mathrm{C}=\mathrm{O})$ of hemicelluloses was observed at $1740 \mathrm{~cm}^{-1}$. The dissolution of hemicellulose into [BMIM] [Cl] caused some decrease in the intensity of acetyl group of both biomass along with the treatment time. Comparing OPF and bam- boo, the acetyl group of hemicellulose of OPF decomposed more rapidly after the IL treatment.

The lignin characteristics of OPF and bamboo were shown at absorbance band of 1519 and $1629 \mathrm{~cm}^{-1}$ which were corresponded to aromatic $\mathrm{C}=\mathrm{C}$ bending and $\mathrm{C}=\mathrm{C}$ stretching, respectively [18]. The intensity of lignin characteristics for OPF and bamboo decreased along the treatment time indicating that lignin dissolved into IL after treatment.

A sharp and narrow band observed at 1168 $\mathrm{cm}^{-1}$ and this was possibly due to the deposition of [BMIM] $[\mathrm{Cl}]$ in the non-soluble products as it did not evaporate during the drying process. This result was similar to a previous research showing the same residue spectra [28].

The X-ray diffraction patterns for OPF and bamboo before and after treatment are shown in Figure 6. Two microcrystalline characteristic diffraction peaks of cellulose I structure were observed at $15.7^{\circ}$ and $22.6^{\circ}$ which showed the presence of undisrupted crystalline structure. After 24 hours of IL treatment, the peaks became weaker and broader which indicates the decrease in crystallinity due to distortion and disruption of crystalline cellulose I. Another

\section{OPF}

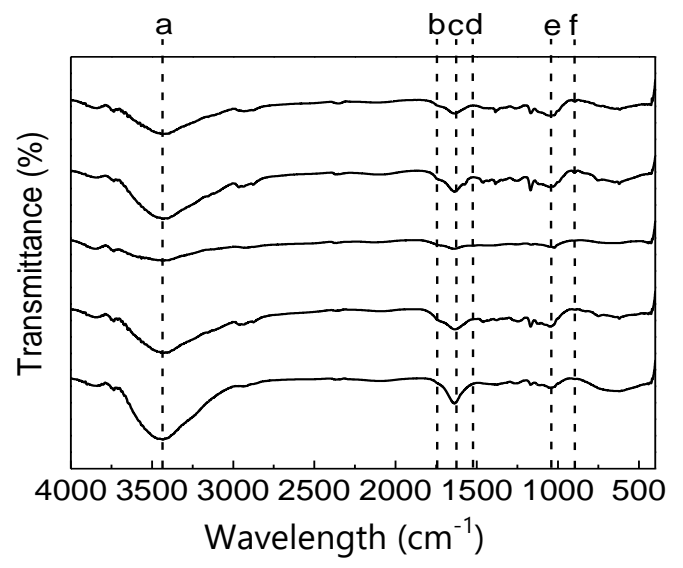

\section{Bamboo}

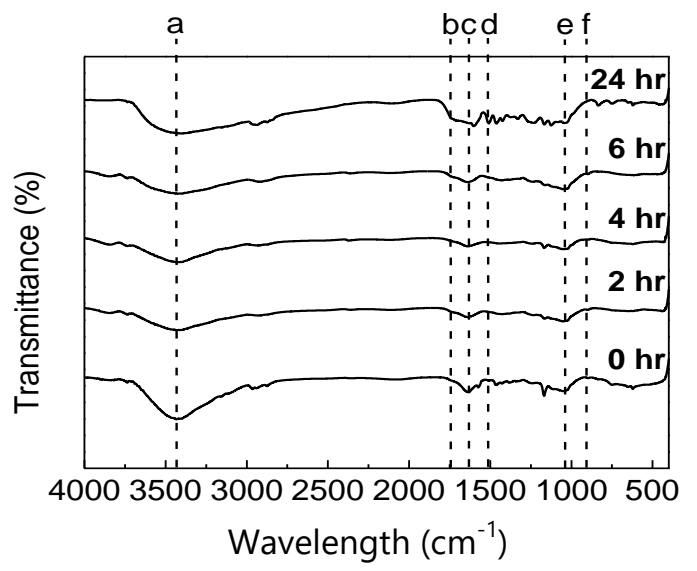

Figure 5. FTIR spectra of the untreated and treated OPF and bamboo

Table 1. FTIR spectra of untreated and treated OPF and bamboo

\begin{tabular}{cll}
\hline Line & Band $\left(\mathrm{cm}^{-1}\right)$ & Group \\
\hline a & 3433 & O-H stretching vibration \\
b & 1740 & C=O of acetyl group \\
c & 1629 & C=C stretching (lignin) \\
d & 1519 & Aromatic C=C stretching (lignin) \\
e & 1050 & C-O stretching vibration (derived from cellulose I) \\
f & 895 & C-H deformation vibration (derived from non-crystalline cellulose II) \\
\hline
\end{tabular}


peak at $20.0^{\circ}$ was observed after the prolonged IL treatment. This peak was attributed to amorphous cellulose II formed due to the change in crystallinity of the cellulose structure as the hydrogen network was disrupted by [BMIM][Cl] [29].

The peak of OPF shifted to $20.0^{\circ}$ after 24 hours of treatment showing that most of the cellulose I were disrupted to form amorphous cellulose II. As for bamboo, the peak of cellulose I at $22.6^{\circ}$ was still visible indicates the presence of significant amount of cellulose I after treatment. This was because the cell wall structure of bamboo was not fully distorted due to its more complex structure nature.

The morphological structures of OPF and bamboo before treatment and after 24 hours of $[\mathrm{BMIM}][\mathrm{Cl}]$ treatment are illustrated in Figure 7. At 0 hour, the structures of cell wall of both $\mathrm{OPF}$ and bamboo were in ordered and compact form. After prolonged treatment $(24 \mathrm{~h})$, the cell walls were not clearly be seen which indicates
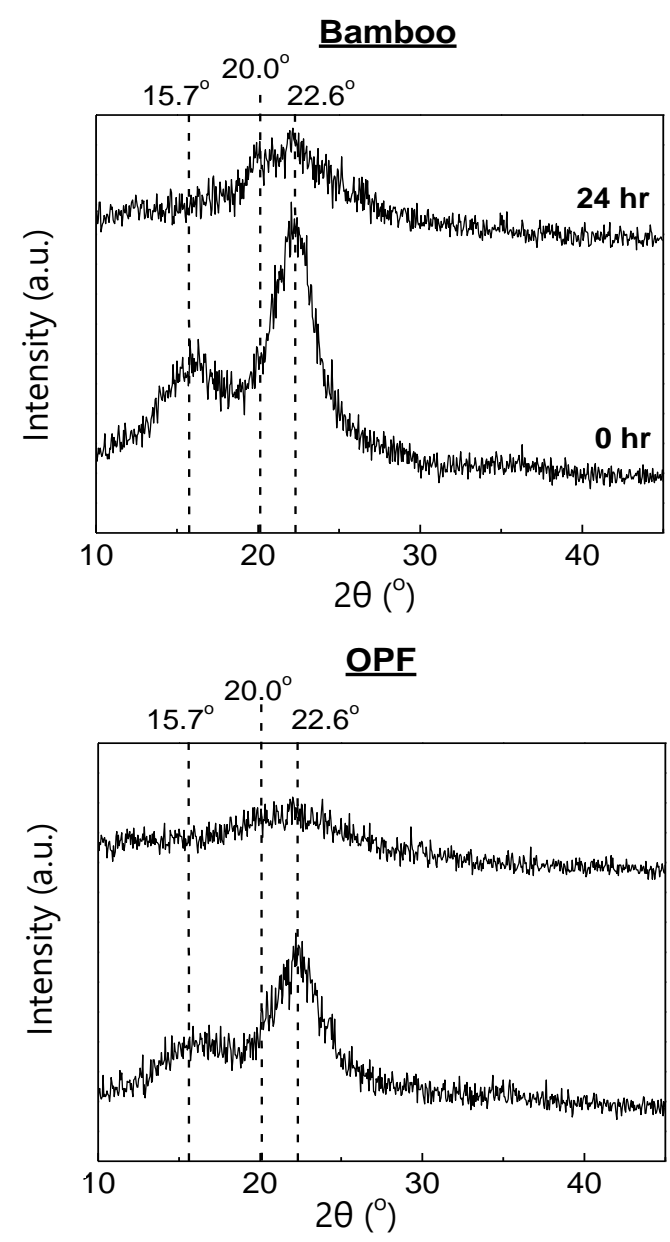

Figure 6. XRD patterns of OPF and bamboo before and after 24 hours of treatment with $[\mathrm{BMIM}][\mathrm{Cl}]$ that [BMIM][Cl] effectively disrupts the intricate cell wall network of lignocelluloses [30]. The intra- and intermolecular hydrogen bonding of cellulose was broken, causing the crystalline structure of biomass to disintegrate and formed the amorphous structure [31].

Comparing the morphological structure of untreated $\mathrm{OPF}$ and bamboo, the edge of the cell walls of bamboo overlapped on each other resulting in a more complex structure. After prolonged treatment, the structure of OPF became a homogenous macrostructure signifying the more rapid dissolution rate compared to bamboo due to greater distortion on hydrogen bonding network within cell wall and this was consistent to XRD analysis. This result was similar to a previous study reporting that the dissolution rate was higher when the cell wall structure was less complex and compact [14].

\subsection{BMIM][Cl]-soluble}

Sugar derivatives of OPF and bamboo after [BMIM][Cl] treatment are demonstrated in Figure 8. There were four major mono-sugars in $\mathrm{OPF}$ and bamboo [BMIM][Cl]-soluble fractions, which included glucose, xylose, mannose and arabinose. During the IL treatment, glucose was partially produced from cellulose while mannose, xylose, and arabinose were derived from hemicellulose. The intensity of these sugar derivatives became stronger after prolonged treatment which probably due to the hydrolyzation of cellulose and hemicellulose during the liquefaction time. Significant peak of mono-sugar was observed in OPF after short period (2 hours) of treatment. This result signifies the amount of solubilized polymer of $\mathrm{OPF}$ was greater and easier to be broken down compared to bamboo.
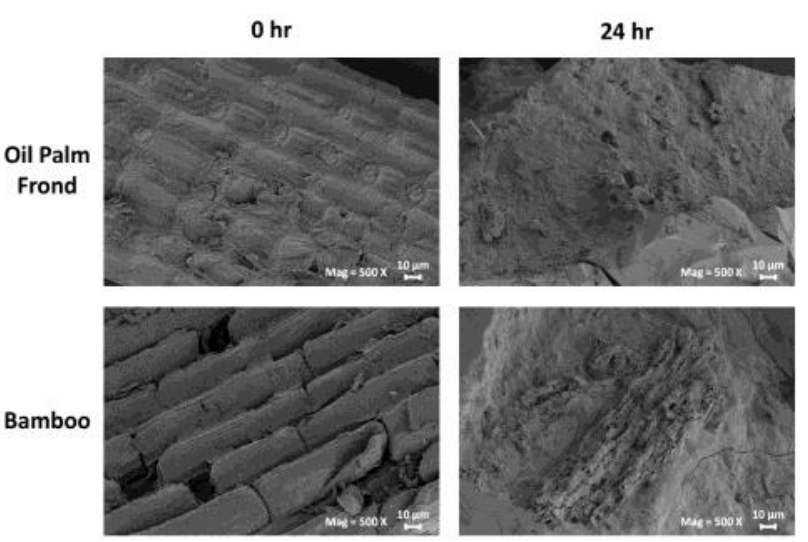

Figure 7. FESEM images of the morphological structures of untreated and treated OPF and bamboo (magnification: $500 \mathrm{X}$ ) 

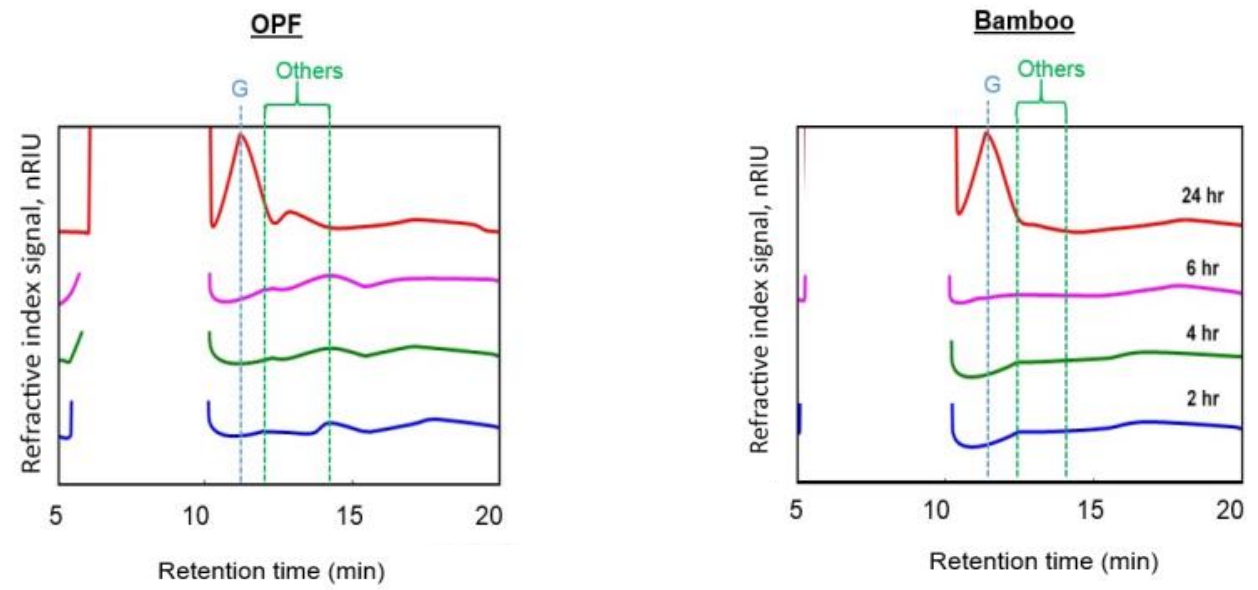

Figure 8. Sugar derivatives of $\mathrm{OPF}$ and bamboo after treatment with [BMIM][Cl] (G: Glucose, Others: Xylose, mannose, and arabinose)

\section{Conclusions}

In a nutshell, the dissolution of OPF in $[\mathrm{BMIM}][\mathrm{Cl}]$ was higher compared to bamboo due to its less complex and compact cell wall structure nature. Thus, the diffusion of [BMIM] $[\mathrm{Cl}]$ into the interior cell wall of OPF was much easier and the hydrogen bonding network was broken more efficiently. As the result, the crystalline structure of cellulose of OPF was decomposed more rapidly along the treatment time than bamboo and more holocelluloses and lignin was solubilized into [BMIM][Cl]. Not to mention, the mono-sugars of OPF was formed much easily after 2 hours of [BMIM][Cl] treatment which indicates that the amount of solubilized polymer of OPF was greater than bamboo and easier to be broken down.

\section{Acknowledgments}

The authors would like to express their gratitude to Chemical Reaction Engineering Group (CREG, UTM) for providing the research facilities which makes this research viable and effective. Next, deepest appreciation was extended to Universiti Teknologi Malaysia (UTM) for supporting this research under Fundamental Research Grant Scheme (vote 4F160).

\section{References}

[1] Verheye, W. (2007). Growth and Production of Oil Palm. In Verheye, W. (ed.) Encyclopedia of Life Support Systems (EOLSS). Oxford, UK: UNESCO-EOLSS Publishers.

[2] Sime Darby. (3 March 2015). Palm Oil Facts and Figures URL http://www.simedarby.com/upload/Palm_Oil_Facts_and_Figures.pdf.
[3] Shibata, M., Varman, M., Tono, Y., Miyafuji, H., Saka, S. (2008). Characterization in Chemical Composition of the Oil Palm (Elaeis Guineensis). Journal of the Japan Institute of Energy, 87(5): 383-388.

[4] Wang, D., Shen, S.J. (1987). Bamboos of China. Oregon: Timber Press.

[5] Ahmad, M. (2000). Analysis of Calcutta Bamboo for Structural Composite Materials. Doctor Philosophy, Universiti Teknologi MARA.

[6] Liese, W. (1985). Anatomy and Properties of Bamboo. In International Bamboo Workshop, 197-208. Hangzhou, China.

[7] Fengel, D., Wegener, G. (1983). Wood: Chemistry, Ultrastructure and Reactions. Berlin: Walter de Gruyter and Company.

[8] Howard, R.L., Abotsi, E., van Rensburg, J., Howard, S. (2003). Lignocellulose Biotechnology: Issues of Bioconversion and Enzyme Production. African Journal of Biotechnology, 2(12): 602-609.

[9] Chandra, R.P., Bura, R., Mabee, W.E., Berlin, A., Pan, B., Saddler, J.N. (2007). Substrate Pretreatment: The Key to Effective Enzymatic Hydrolysis of Lignocellulosics? Advances in Biochemical Engineering/ Biotechnology, 108: 67-93.

[10] Bonhôte, P., Dias, A.P., Papageorgiou, N., Kalyansundaram, K., Gratzel, M. (1996). Hydrophobic, Highly Conductive AmbientTemperature Molten Salts. Inorganic Chemistry, 35(5): 1168-1178.

[11] Brennecke, J.F., Maginn, E.J. (2001). Ionic Liquids: Innovative Fluids for Chemical Processing. AIChE Journal, 47(11): 2384-2389.

[12] Hapiot, P., Lagorst, C. (2008). Electrochemical Reactivity in Room-temperature Ionic Liquids. Chemical Reviews, 108(7): 2238-2264. 
[13] Olivier-Bourbigou, H., Magna, L., Morvan, D. (2010). Ionic Liquids and Catalysis: Recent Progress from Knowledge to Applications. Applied Catalysis A: General, 373(1-2): 1-56.

[14] Kilpeläinen, I., Xie, H., King, A., Granstrom, M., Heikkinen, S., Argyropoulos, D.S. (2007). Dissolution of Wood in Ionic Liquids. Journal of Agricultural and Food Chemistry, 55(22): 9142-9148.

[15] Yokoo, T., Miyafuji, H. (2014). Reaction Behavior of Wood in an Ionic Liquid, 1-Ethylpyridinium Bromide. Journal of Wood Science, 60(5): 339-345.

[16] Nakamura, A., Miyafuji, H., Saka, S. (2010). Liquefaction Behavior of Western Red Cedar and Japanese Beech in the Ionic Liquid 1-Ethyl-3-methylimidazolium Chloride. Holzforschung, 64(3): 289-294.

[17] Fort, D.A., Remsing, R.C., Swatloksi, R.P., Moyna, P., Moyna, G., Rogers, R.D. (2007). Can Ionic Liquids Dissolve Wood? Processing and Analysis of Lignocellulosic Materials with 1-n-Butyl-3-methylimidazolium Chloride. The Royal Society of Chemistry, 9:63-69.

[18] Ramli, M., Amin, N.A.S., Ware, I. (2014). Optimization of Oil Palm Fronds Pretreatment Using Ionic Liquid for Levulinic Acid Production. Jurnal Teknologi, 71(1): 33-41.

[19] Tan, H.T., Lee, K.T., Mohamed, A.R. (2011). Pretreatment of Lignocellulosic Palm Biomass Using A Solvent-Ionic Liquid [BMIM]Cl for Glucose Recovery: An Optimisation Study Using Response Surface Methodology. Carbohydrate Polymers, 83(4): 1862-1868.

[20] Kureel, S., Pandey, R., Bhanja, H. (2014). Pre-treatment of Bamboo with 1-Butyl-3methylimidazolium Chloride [BmimCl] for Production of Fermentable Sugars by Enzymatic Hydrolysis. International Journal of Emerging Technology and Advanced Engineering, 4(7): 733-735.

[21] Wang, F., Li, S., Sun, Y., Han, H., Zhang, B., Hu, B., Gao, Y., Hu, X. (2017). Ionic Liquids as Efficient Pretreatment Solvents for Lignocellulosic Biomass. RSC Advances, 7: 4799047998 .

[22] Feng, L., Chen, Z.I. (2008). Research Progress on Dissolution and Functional Modification of cellulose in Ionic Liquids. Journal of Molecular Liquids, 142(1-3): 1-5.
[23] Swatloski, R.P., Spear, S.K., John, D.D.H.J., Rogers, R.D. (2002). Dissolution of Cellulose with Ionic Liquids. Journal of American Chemical Society, 124(18): 4974-4975.

[24] Wei, L., Li, K., Ma, Y., Hou, X. (2012). Dissolving Lignocellulosic Biomass in a 1-Butyl3-methylimidaozlium Cloride-water Mixture. Industrial Crops and Products, 37(1): 227234.

[25] Jakab, E., Faix, O, Till, F. (1997). Thermal Decomposition of Milled Wood Lignins Studied by Thermogravimetry / Mass Spectrometry. Journal of Analytical and Applied Pyrolysis, 40-41: 171-186.

[26] Parmon, M.K.J. (2014). The Liquefaction of Nipa Frond in an Ionic Liquid, 1-Butyl-3methylimidazolium Chloride. Bachelor of Engineering (Chemical), Universiti Teknologi Malaysia.

[27] Kamarludin, S.N.C., Ubong, S., Idris, N., Azmi, I.S., Jainal, M.S., Jalil, R., Omar, W.S. A.W.Z.M.T.E.T., Safaai, N.S.M., Azizan, A. (2014). Imidazolium-based Ionic Liquid Dissolution Influence on Crystallinity of Oil Palm Frond, Oil Palm Trunk and Elephant Grass Lignocellulosic Biomass. Advanced Materials Research, 911: 307-313.

[28] Shibata, M., Yamazoe, K., Kuribayashi, M., Okuyama, Y. (2013). All-wood Biocomposites by Partial Dissolution of Wood Flour in 1Butyl-3-methylimidazolium Chloride. Journal of Applied Polymer Science, 127(6): 48024808.

[29] Muhammad, N., Man, Z., Bustam, M.A., Mutalib, M.I.A., Wilfred, C.D., Rafiq, S. (2011). Dissolution and Delignification of Bamboo Biomass using Amino Acid-Based Ionic Liquid. Applied Biochemistry and Biotechnology, 165(3-4): 998-1009.

[30] Wang, X., Li, H., Cao, Y., Tang, Q. (2011). Cellulose Extraction from Wood Chip in An Ionic Liquid 1-Allyl-3-methylimidazolium Chloride (AmimCl). Bioresource Technology, 102(17): 7959-7965.

[31] Katinonkul, W., Lee, J.S., Ha, S.H., Park, J.Y. (2012). Enhancement of Enzymatic Digestibility of Oil Palm Empty Fruit Bunch by Ionic-liquid Pretreatment. Energy, 47(1): 1116. 